\section{Low GWP alternatives to HFC-245fa in Organic Rankine Cycles for recovery of low temperature heat: HCFO-1233zd-E and HFO-1336mzz-Z}

Francisco Molés ${ }^{1, a}$, Joaquín Navarro-Esbría ${ }^{2}$ Bernardo Peris ${ }^{\mathrm{a}}$, Adrián Mota-Babiloni ${ }^{\mathrm{b}}$, Ángel Barragán-Cervera ${ }^{\mathrm{a}}$ Konstantinos (Kostas) Kontomaris ${ }^{\mathrm{c}}$

${ }^{a}$ ISTENER Research Group. Department of Mechanical Engineering and Construction, Campus de Riu Sec s/n, University Jaume I, E12071, Castellón (Spain).

${ }^{\mathrm{b}}$ Departamento de Ingeniería Química y Nuclear, Universidad Politécnica de Valencia, Camino de Vera 14, Valencia (Spain).

${ }^{\mathrm{c}}$ DuPont Fluorochemicals R\&D, Chestnut Run Plaza, P.O.Box 2915, Wilmington, Delaware 19805, USA

\begin{abstract}
HFC-245fa is a common working fluid used in Organic Rankine Cycles generating mechanical power from low temperature heat. This paper compares the predicted ORC performance of two novel low GWP working fluids, HCFO-1233zd-E and HFO$1336 \mathrm{mzz}-\mathrm{Z}$, to HFC-245fa over a wide range of evaporating temperatures, condensing temperatures and vapor superheat values. Expander power output, required pump power input, net cycle efficiencies, mass flow rates and turbine size parameters with HCFO-1233zd-E, HFO-1336mzz-Z and HFC-245fa were compared for a given thermal power input. HCFO-1233zd-E and HFO-1336mzz-Z are predicted to have attractive thermodynamic Rankine power cycle performance. HCFO-1233zd-E would require 10.3 to $17.3 \%$ lower pump power and would enable up to $10.6 \%$ higher net cycle efficiencies than HFC-245fa over the range of cycle conditions examined in this paper. The turbine size required with HCFO-1233zd-E would be up to about $7.5 \%$ to $10.2 \%$ larger than with HFC-245fa. HFO-1336mzz-Z would require $36.5 \%$ to $41 \%$ lower pump power and would enable up to $17 \%$ higher net cycle efficiencies than HFC-245fa over the range of cycle conditions examined in this paper. The turbine size required with HFO-1336mzz-Z would be up to about $30.9 \%$ to $41.5 \%$ larger than with HFC$245 \mathrm{fa}$. HFO-1336mzz-Z cycle efficiency is benefitted substantially by a recuperator. The net cycle efficiency increases and the required turbine size decreases relative to HFC-245fa for HCFO-1233zd-E and, especially, for HFO-1336mzz-Z at higher evaporating and condensing temperatures.
\end{abstract}

Keywords: low GWP fluids; HFC-245fa; ORC systems; low temperature heat sources.

\begin{tabular}{|l|}
\hline Nomenclature \\
ORC Organic Rankine Cycle
\end{tabular}

${ }^{1}$ Corresponding Author:

Tel: +34 964387529; fax: +34 964728106.

E-mail address: molesf@uji.com
Formatat: anglès (EUA)

Formatat: anglès (EUA) 
PEL permissible exposure level (ppm)

ALT atmospheric life time (yr)

ODP ozone depletion potential

GWP global warming potential

$\mathrm{T} \quad$ temperature $(\mathrm{K})$

$\mathrm{P} \quad$ pressure $(\mathrm{kPa})$

h enthalpy $(\mathrm{kJ} / \mathrm{kg})$

s entropy $(\mathrm{kJ} / \mathrm{kgK})$

w specific work $(\mathrm{kJ} / \mathrm{kg})$

$\dot{m} \quad$ mass flow rate $(\mathrm{kg} / \mathrm{s})$

$\dot{V} \quad$ volumetric flow rate $\left(\mathrm{m}^{3} / \mathrm{h}\right)$

W electric power $(\mathrm{kW})$

Q thermal power $(\mathrm{kW})$

SP turbine size parameter

Greek symbols

$\varepsilon \quad$ regenerator effectiveness

$\eta \quad$ efficiency

Subscripts

c critical

evap evaporator

cond condenser

p pump

x expander

v volumetric

is isentropic 


\begin{tabular}{|ll|} 
em & electromechanical \\
i & inlet \\
o & outlet \\
n net & \\
\hline
\end{tabular}

\section{Introduction}

Due to environmental constrains, Combined Heat and Power (CHP) systems and bottoming power cycles for waste heat recovery have received considerable attention over the past decades. Several power cycles have been proposed for low temperature heat recovery. Among them, the Organic Rankine Cycle (ORC) has been attracting increasing attention. Several ORC systems have been installed for recovering waste heat from cement [1] or oil industry [2] operations or from internal combustion engines [3]. ORC systems have also been widely used for converting renewable energy, such as solar [4], biomass [5] and geothermal [6] energy into power. ORCs have been studied by various authors, commonly classifying heat sources with temperatures ranging between $100^{\circ} \mathrm{C}$ and $250^{\circ} \mathrm{C}$ as "low temperature" heat sources and between $250^{\circ} \mathrm{C}$ and $600^{\circ} \mathrm{C}$ as "high temperature" heat sources. Brasz et al. [7] considered low temperature applications and Zabek et al. [8] studied waste heat recovery at high temperatures, demonstrating ORC feasibility in both cases.

The choice of the ORC working fluid has an important influence on the system efficiency, and numerous works on this subject can be found in the literature. Lai et al. [9] investigated potential pure working fluids for high temperature ORC processes and found that siloxanes and selected hydrocarbons are promising. Shale et al. [10], Shengjun et al. [11] and Quoilin et al. [12] evaluated different working fluids for low to medium temperature applications, highlighting that hydrofluorocarbons with low critical temperatures, such as HFC-134a and HFC-245fa, are suitable. Moreover Quoilin et al. [13] highlighted that HFC-245fa is a common working fluid in commercial ORC installations, mainly used in waste heat recovery from low temperature sources. Additionally they observed that, at the present time, most commercial ORC plants exhibit a simple architecture: sub-critical working conditions, pure working fluids, single evaporation pressure, and possible use of a recuperator heat exchanger.

Attending to environmental issues, HFC-245fa is a hydrofluorocarbon (HFC) with zero Ozone Depletion Potential (ODP). However, the environmental impact of a working fluid, when it escapes to the atmosphere, is not limited to stratospheric ozone layer depletion. In fact, while all HFCs are harmless to the earth's stratospheric ozone layer, some HFCs with large Global Warming Potentials (GWP) could contribute significantly to climate change. In 1997 HFCs were designated as greenhouse gases and currently they are targeted for greenhouse gas emissions reductions under the Kyoto Protocol [14]. As a result, alternatives are sought for high GWP HFCs, such as HFC-245fa, which has a GWP of 1030 .

Some low GWP working fluids are being studied to replace HFC-245fa in various applications, including ORC systems. One of them is HCFO-1233zd-E [15], a 
hydrochlorofluoroolefin (HCFO) with a GWP of 7. Despite the presence of chlorine in the molecule of HCFO-1233zd-E some studies have concluded that its ODP is very small (0.00034) due to its very short atmospheric lifetime [16]. Another candidate to replace HFC-245fa in ORC systems is HFO-1336mzz-Z, also known as DR-2, a hydrofluoroolefin (HFO) with a GWP of 9 and zero ODP [17-21]. Table 1 shows the main thermophysical properties of HFC-245fa, HCFO-1233zd-E and HFO-1336mzz-Z, and Figure 1 shows the temperature-entropy diagrams and vapour pressure curves for these three fluids.

Table 1. Thermophysical properties of HFC-245fa, HCFO-1233zd-E and HFO$1336 \mathrm{mzz}-\mathrm{Z}$.

Fig. 1. T-s diagrams and vapour pressure curves for HFC-245fa, HCFO-1233zd-E and HFO-1336mzz-Z.

In the present work, an evaluation of the low GWP fluids HCFO-1233zd-E and HFO$1336 \mathrm{mzz}-\mathrm{Z}$ as alternatives to HFC-245fa in ORC systems for low temperature heat sources is carried out. The rest of the paper is organized as follows: Section 2 describes the ORC systems considered; Section 3 reports and discusses the main results; finally, Section 4 summarizes the main conclusions.

\section{ORC systems description}

With the aim of studying the feasibility of using low GWP fluids as alternatives to HFC-245fa in ORC systems for low temperature heat recovery, a thermodynamic analysis has been carried out. Two cycle configurations have been considered: the basic cycle and a regenerative cycle.

The Basic Organic Rankine Cycle (BORC) is the simplest configuration, shown in Fig. 2. It works in subcritical conditions and requires a minimum number of equipment components. The working fluid is pumped through the evaporator to take the available heat from the thermal source. The highest enthalpy of the circuit is reduced in the expander to produce mechanical power, which is usually transformed into electricity through a generator. To close the loop, the fluid is condensed, subcooled and pumped again.

Fig. 2. Basic Organic Rankine Cycle (BORC).

The Regenerative Organic Rankine Cycle (RORC) is similar to the BORC, except in that it includes an internal heat exchanger as a regenerator. This configuration uses the superheat in the vapor exiting the expander to preheat the pressurized liquid entering the evaporator, reducing at the same time the thermal load on the condenser. 
Fig. 3. Regenerative Organic Rankine Cycle (RORC).

The basic equations used to model each configuration are listed in Table 2. The thermodynamic properties of HFC-245fa and HCFO-1233zd-E were obtained from the Refprop database [22]. The thermodynamic properties of HFO-1336mzz-Z were provided by DuPont. The basic operating parameters that determine cycle performance were specified as indicated in Table 3. When varying a parameter the rest of them were maintained constant at the values shown in parentheses. The subcooling, the expander and pump efficiencies and the regenerator effectiveness were kept constant.

Table 2. Model equations for each configuration.

Table 3. Operating parameters.

\section{Results and discussion}

The expander power output, required pump power input, net cycle efficiencies, mass flow rates and turbine size parameters [23] for the three fluids of interest were compared for a given heat rate supplied to the evaporator. (add brief description and significance of the "turbine size parameter").

The ORC performance using the three working fluids of interest is compared for a wide range of evaporating temperatures, condensing temperatures and superheat values. In a first analysis the evaporating temperature was varied according to Table 3 , maintaining the condensing temperature at $300 \mathrm{~K}\left(27{ }^{\circ} \mathrm{C}\right)$ and the superheat at $5 \mathrm{~K}$. In CHP applications, it could be interesting to consider higher condensing temperatures. A second analysis was carried out varying the condensing temperature according to Table 3 , while maintaining the evaporating temperature at $400 \mathrm{~K}\left(127^{\circ} \mathrm{C}\right)$ and the superheat at $5 \mathrm{~K}$. However, some studies [24] have remarked that, depending on the heat source conditions, superheat may be needed to maximize the net cycle power generation. A third analysis was performed varying the superheat according to Table 3 while maintaining the evaporating temperature at $400 \mathrm{~K}\left(127{ }^{\circ} \mathrm{C}\right)$ and the condensing temperature at $300 \mathrm{~K}\left(27^{\circ} \mathrm{C}\right)$.

In order to compare each alternative fluid performance with HFC-245fa, the results are shown in terms of relative difference taking HFC-245fa as reference, calculated as shown in Eq. 1.

$$
\% X=\frac{X_{R 1233 z d / R 1336 m z z}-X_{R 245 f a}}{X_{R 245 f a}}
$$

Fig. 4 shows the relative differences, taking HFC-245fa as reference, for expander power output varying the evaporating temperature, condensing temperature and 
superheat. Focusing on the BORC configuration, the relative differences are between $1.8 \%$ and $3.3 \%$ for HCFO-1233zd-E and between $-5.2 \%$ and $-2.4 \%$ for HFO-1336mzz-

$\mathrm{Z}$. Attending to the RORC configuration, the relative differences are between $-0.2 \%$ and $1.4 \%$ for HCFO-1233zd-E and between $-1.7 \%$ and 3.5\% for HFO-1336mzz-Z. For both fluids the expander power output is higher than that obtained using HFC-245fa for high evaporating temperatures, low condensing temperatures and low values of superheat.

Fig. 4. Relative differences, taking HFC-245fa as reference, for expander power output varying: (a) evaporating temperature, (b) condensing temperature, and (c) superheat.

Fig. 5 shows the relative differences, taking HFC-245fa as reference, for pump power input varying the evaporating temperature, condensing temperature and superheat. For HCFO-1233zd-E the relative differences are between $-10.3 \%$ and $-17.3 \%$, while for HFO-1336mzz-Z are between $-36.5 \%$ and $-41 \%$. For both cycle configurations, HCFO1233zd-E and HFO-1336mzz-Z consume lower pump power than HFC-245fa throughout the range of operating conditions examined. This reduction in pump power consumption can be explained attending to the lower working pressures of both low GWP fluids relative to HFC-245fa, as seen in the vapour pressure curves in Fig. 1.

Fig. 5. Relative differences, taking HFC-245fa as reference, for pump power input varying: (a) evaporating temperature, (b) condensing temperature, and (c) superheat.

Fig. 6 shows the relative differences, taking HFC-245fa as reference, for net cycle efficiency varying the evaporating temperature, condensing temperature and superheat. The improvements in the net cycle efficiency for HCFO-1233zd-E relative to HFC$245 \mathrm{fa}$ are between $1.7 \%$ and $10.6 \%$, and for HFO-1336mzz-Z are between $-0.3 \%$ and $17 \%$. In the BORC configuration, HFO- $1336 \mathrm{mzz}-Z$ presents higher net cycle efficiencies than HCFO-1233zd-E at condensing temperatures higher than about $326 \mathrm{~K}$ $\left(53{ }^{\circ} \mathrm{C}\right)$. In the RORC configuration, HFO-1336mzz-Z presents higher net cycle efficiencies than HCFO-1233zd-E throughout the range of operating conditions examined. For both cycle configurations and both low GWP working fluids, the improvements in net cycle efficiency are larger for high evaporating temperatures, high condensing temperatures and low values of superheat.

Fig. 6. Relative differences, taking HFC-245fa as reference, for net cycle efficiency varying the: (a) evaporating temperature, (b) condensing temperature, and (c) superheat.

Fig. 7 shows the relative differences, taking HFC-245fa as reference, for mass flow rate varying evaporating temperature, condensing temperature and superheat. HCFO$1233 z d-E$ presents mass flow rates comparable to HFC-245fa, with relative differences between $-2.4 \%$ and $4.3 \%$ depending on the operating conditions. HFO-1336mzz-Z presents mass flow rates higher than HFC-245fa by $1.5 \%$ to $10.7 \%$, being higher for the RORC configuration than for the BORC configuration. For both fluids, the relative 
differences for mass flow rate are higher for low evaporating temperatures, low condensing temperatures and high values of superheat.

Fig. 7. Relative differences, taking HCFO-245fa as reference, for mass flow rate varying the: (a) evaporating temperature, (b) condensing temperature, and (c) superheat.

Fig. 8 presents the relative differences, taking HFC-245fa as reference, for the turbine size parameter varying evaporating temperature, condensing temperature and superheat. The turbine size parameter for HCFO-1233zd-E is between $7.5 \%$ and $10.2 \%$ higher than for HFC-245fa, while for HFO-1336mzz-Z is between $30.9 \%$ and $41.5 \%$ higher than for HFC-245fa. For HCFO-1233zd-E the relative differences are higher for the BORC configuration, while for HFO-1336mzz-Z are higher for the RORC configuration. [Would the rotating speed with HFO-1336mzz-Z be lower vs HCFO-1233zd-E and HFC-245fa? Would a lower rotating speed result in higher expander efficiency for HFO-1336mzz-Z?]

Fig. 8. Relative differences, taking HFC-245fa as reference, for turbine size parameter varying: (a) evaporating temperature, (b) condensing temperature, and (c) superheat.

\section{Conclusions}

In this paper a theoretical evaluation of the low GWP fluids HCFO-1233zd-E and HFO$1336 \mathrm{mzz}-\mathrm{Z}$ as alternatives to HFC-245fa in ORC systems for low temperature heat sources was carried out. A major difference between these fluids attending to ORC performance is the required pump power input. Throughout the range of operating conditions and configurations examined in this paper, HCFO-1233zd-E and HFO$1336 \mathrm{mzz}-\mathrm{Z}$ would consume lower pump power than HFC-245fa by $10.3 \%$ to $17.3 \%$ and $36.5 \%$ to $41 \%$, respectively. Another important difference is the turbine size parameter that is higher than HFC-245fa for both fluids. The turbine size for HCFO-1233zd-E would be about $7.5 \%$ to $10.2 \%$ larger than for HFC-245fa, while for HFO-1336mzz-Z about $30.9 \%$ to $41.5 \%$ larger than for HFC-245fa.Finally, it was concluded that ORC systems working with HCFO-1233zd-E or HFO-1336mzz-Z can achieve higher values of net cycle efficiency than those working with HFC-245fa by up to about $10.6 \%$ and $17 \%$, respectively. This increase in net cycle efficiency is accentuated for high evaporating and condensing temperatures, and low values of superheat.

\section{Acknowledgements}

The authors thankfully acknowledge DuPont Corporation for supporting this work.

\section{References}

[1] J. Wang, Y. Dai, L. Gao, Exergy analyses and parametric optimizations for different cogeneration power plants in cement industry, Applied Energy 86 (2006) 941 - 948. 
[2] J.S. Meacher, Organic Rankine Cycle systems for waste heat recovery in refineries and chemical process plants, in: ESL-IE-81-04-90, Proceedings from the $3^{\text {rd }}$ Industrial Energy Technology Conference, Houston, TX, 1981.

[3] I. Vaja, A. Gambarotta, Internal combustion engine (ICE) bottoming with organic Rankine cycles (ORCs), Energy 35 (2010) $1084-1093$.

[4] S. Canada, G. Cohen, R. Cable, D. Brosseau, H. Price, Parabolic trough organic Rankine cycle solar power plant, paper NREL/CP - 550 - 37077, in: Presented at the 2004 DOE Solar Energy Technologies, Denver, Colorado, October 25 - 28, 2004.

[5] M. Badami, M. Mura, Preliminary design and controlling strategies of a smallscale wood waste Rankine Cycle (RC) with a reciprocating steam engine (SE), Energy 34 (2009) $1315-1324$.

[6] D. Tempesti, G. Manfrida, D. Fiaschi, Thermodynamic analysis of two micro CHP systems operating with geothermal and solar energy, Applied Energy 97 (2012) 609 617.

[7] J.J. Brasz, B.P. Biederman, G. Holdmann, Power production from a moderate temperature geothermal resource, in: Proceedings of GRC Annual Meeting, September $25-28^{\text {th }}, 2005$, pp. $729-734$, Reno, NV, USA.

[8] D. Zabek, J. Penton, D. Reay, Optimization of waste heat utilization in oil field development employing a transcritical Organic Rankine Cycle (ORC) for electricity generation, Applied Thermal Engineering 59 (2013) 363 - 369.

[9] N.A. Lai, M. Wendland, J. Fischer, Working fluids for high-temperature organic Rankine cycles, Energy 36 (2011) 199 - 211.

[10] B. Saleh, G. Koglbauer, M. Wendland, J. Fischer, Working fluids for lowtemperature organic Rankine cycles, Energy 32 (2007) 1210 - 1221.

[11] Z. Shengjun, W. Huaixin, G. Tao, Performance comparison and parametric optimization of subcritical Organic Rankine Cycle (ORC) and transcritical power cycle system for low-temperature geothermal power generation, Applied Energy 88 (2011) $2740-2754$

[12] S. Quoilin, S. Declaye, B.F. Tchanche, V. Lemort, Thermo-economic optimization of waste heat recovery organic Rankine cycles, Applied Thermal Engineering 31 (2011) $2885-2893$

[13] S. Quoilin, M. Van Den Broek, S. Declaye, P. Dewallef, V. Lemort, Technoeconomic survey of Organic Rankine Cycle (ORC) systems, Renewable and Sustainable Energy Reviews 22 (2013) 168 - 186.

[14] Kyoto Protocol, Report of the Conference of the Parties, United Nations Framework Convention on Climate Change (UNFCCC), 1997.

[15] G. Zyhowski, A. Brown, Low Global Warming Fluids for Replacement of HFC- 
245fa and HFC-134a in ORC Applications, ORC 2011 Delft Presentation, 2011.

[16] D. Wang, S. Olsen, D. Wuebbles, Preliminary report: Analyses of tCFP's potential impact on atmospheric ozone, Department of Atmospheric Sciences University of Illinois, Urbana, IL 61801

[17] K. Kontomaris, A low GWP replacement for HCFC-123 in centrifugal chillers: DR-2, paper presented at the UNEP/ASHRAE conference entitled "Road to climate friendly chillers: moving beyond CFCs and HCFCs" on September 30-October 1, 2010 in Cairo, Egypt.

[18] Kontomaris, K.: "Low GWP Working Fluids for Cooling, Heating \& Power: Formatat: anglès (EUA) Weighing the Tradeoffs", ASHRAE-Hellenic Chapter, Athens, Greece, September $7^{\text {th }}$, 2011c.

[19] Kontomaris, K.: "A Zero-ODP, Low GWP Working Fluid for High Temperature Heating and Power Generation from Low Temperature Heat: DR-2", The International Symposium on New Refrigerants and Environmental Technology, Kobe, Japan, Nov. 89, 2012.

[20] Kontomaris, K., B. Minor and B. Hydutsky: "Low GWP Working Fluid for Organic Rankine Cycles: DR-2; Chemical Stability at High Temperatures" $2^{\text {nd }}$ International Seminar on ORC Power Systems, ASME ORC 2013, Rotterdam, The Netherlands, Oct. 7-8, 2013.

[21] Datla, Bala V. and Joost J. Brasz: "Organic Rankine Cycle System Analysis for Low GWP Working Fluids", International Refrigeration and Air Conditioning Conference at Purdue, July 16-19, 2012.

[22] E.W. Lemmon, M.L. Huber, M.O. McLinden, REFPROP, NIST Standard Reference Database 23, v.8, National Institute of Standards, Gaithersburg, MD, USA, 2007.

[23] C. Invermizzi, P. Iora, P. Silva, Bottoming micro-Rankine cycles for micro-gas turbines, Applied Thermal Engineering 27 (2007), 100 - 110.

[24] B. Peris, J. Navarro-Esbrí, F. Molés, Bottoming organic Rankine cycle configurations to increase Internal Combustion Engines power output from cooling water waste heat recovery, Applied Thermal Engineering 61 (2013) $364-371$. 

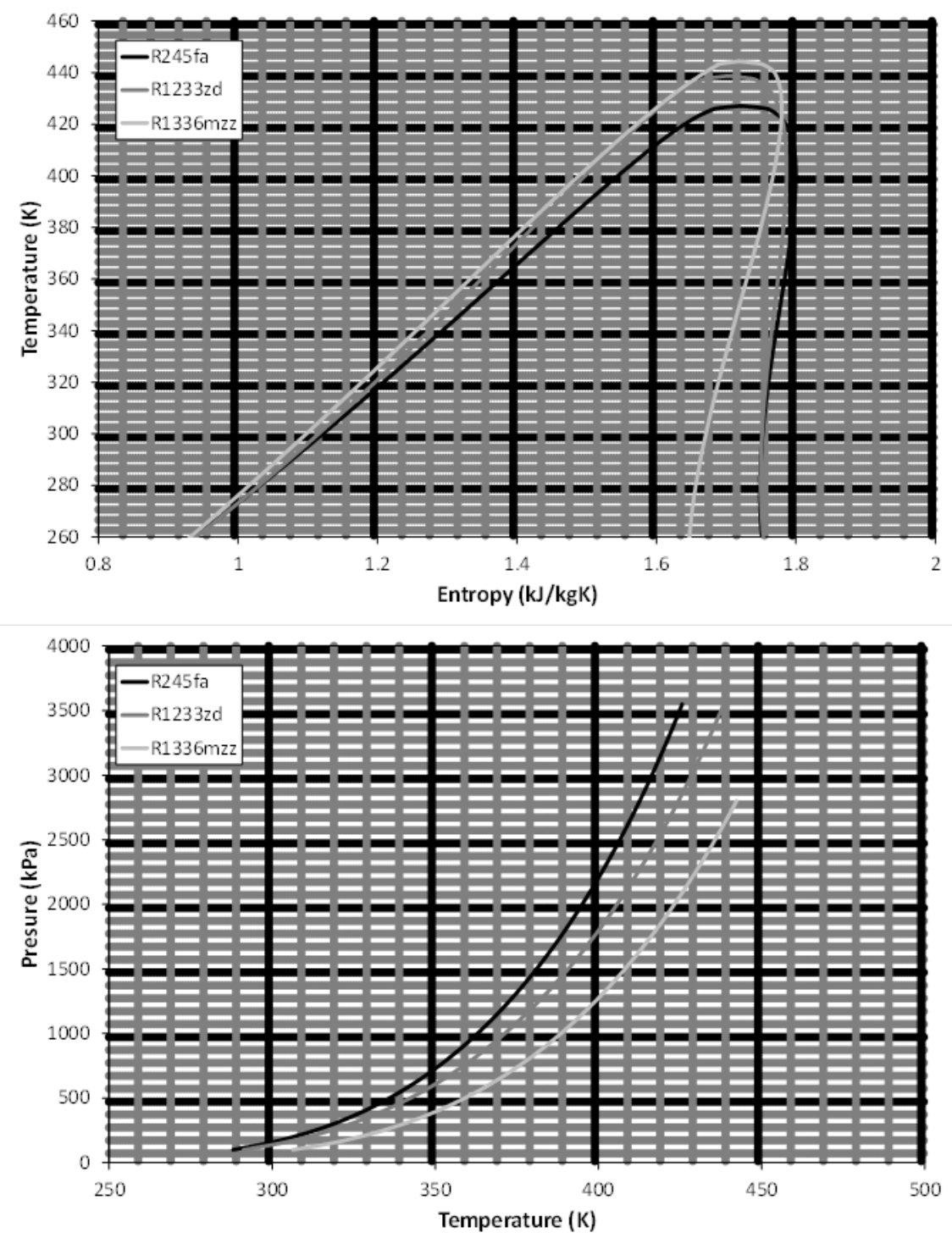

Picture of poor quality; improve

Fig. 1. T-s diagram and vapour pressure curves for HFC-245fa, HCFO-1233zd-E and HFO-1336mzz-Z. 


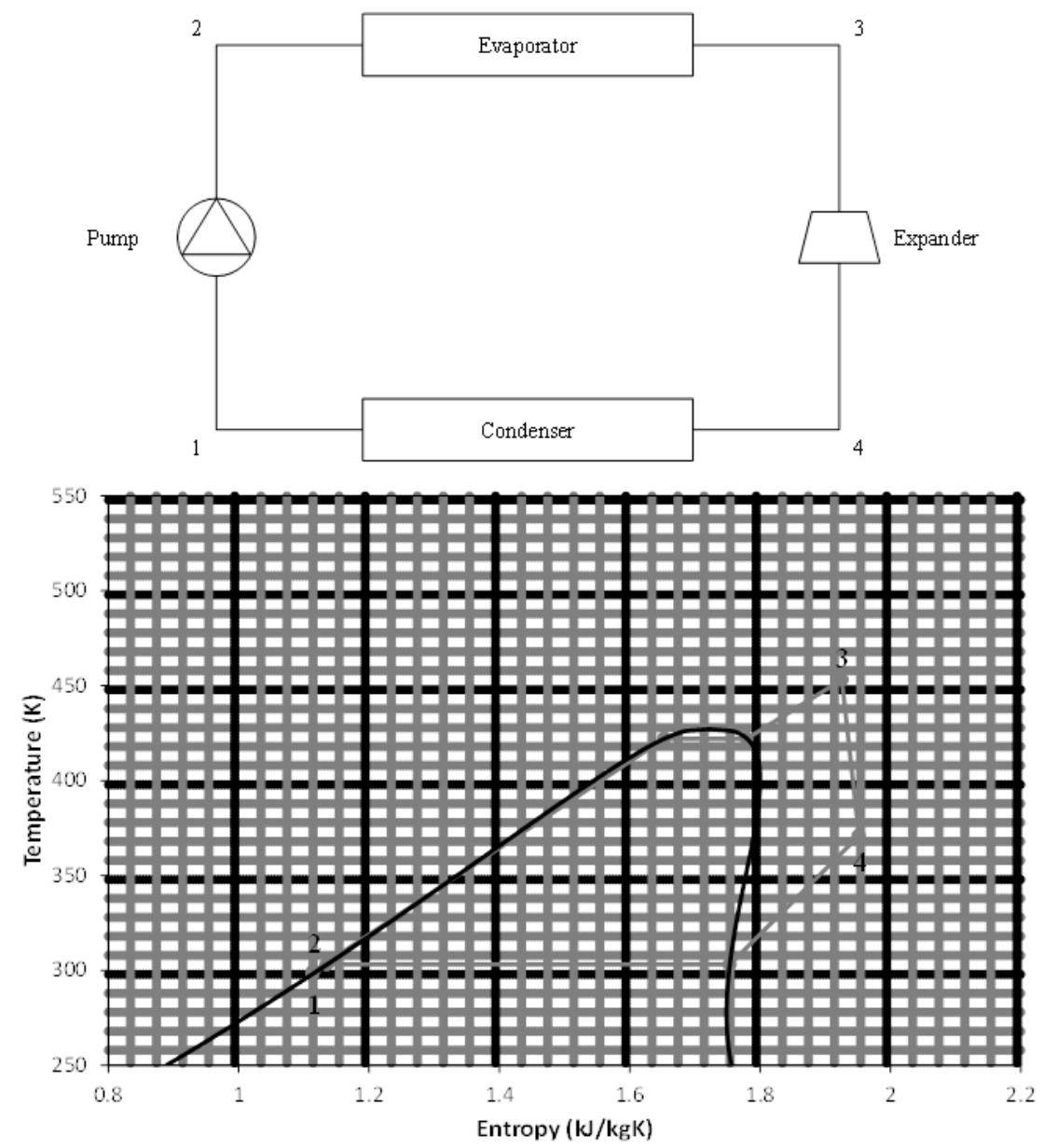

Picture of poor quality; improve

Fig. 2. Basic Organic Rankine Cycle (BORC). 

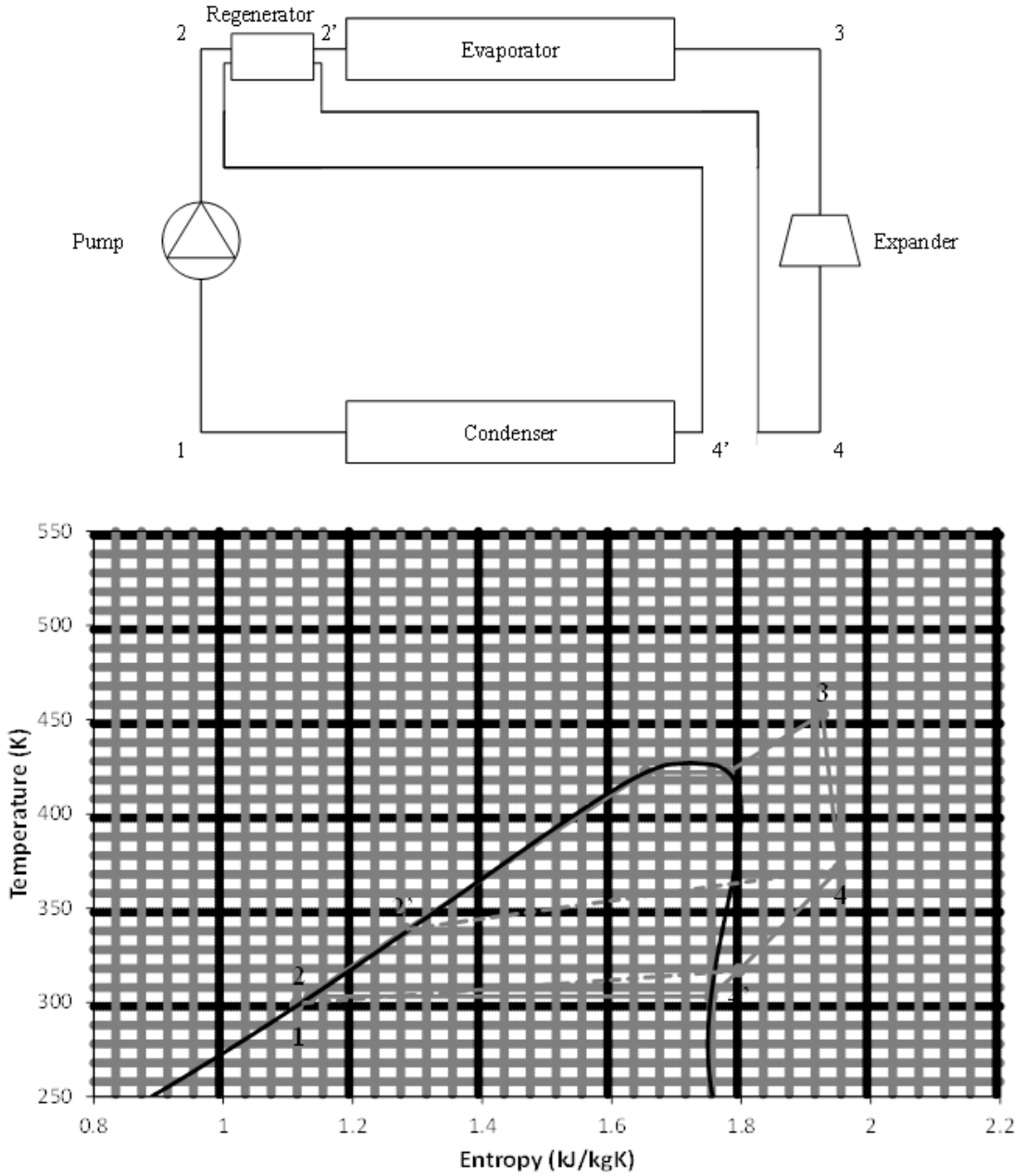

Picture of poor quality; improve

Fig. 3. Regenerative Organic Rankine Cycle (RORC). 


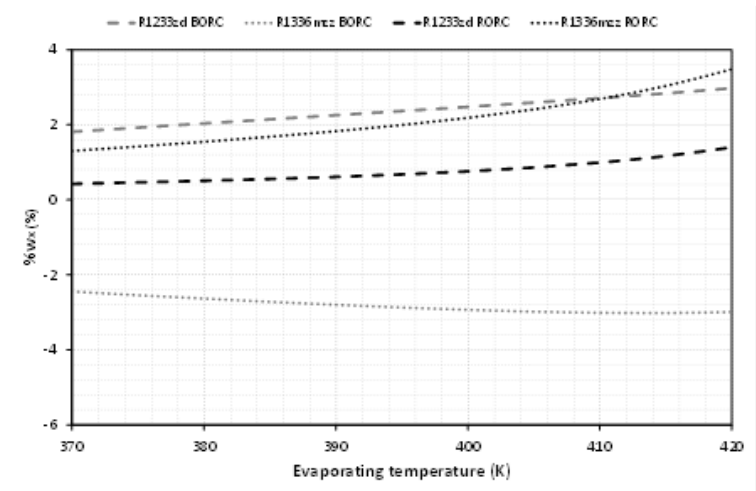

(a) increase font size

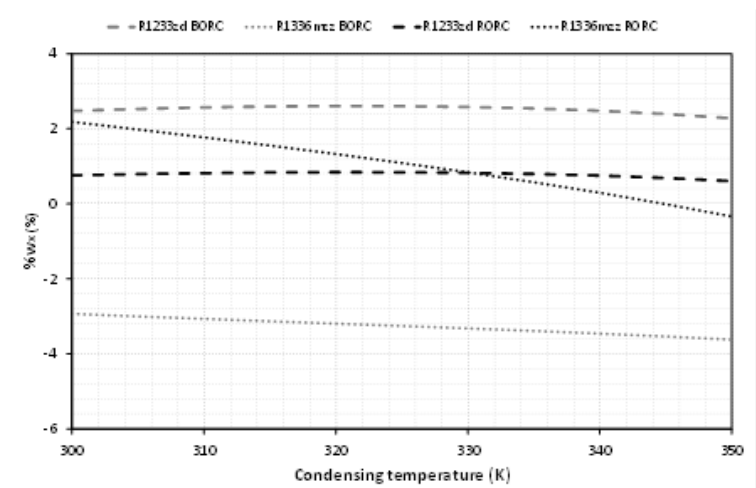

(b) increase font size

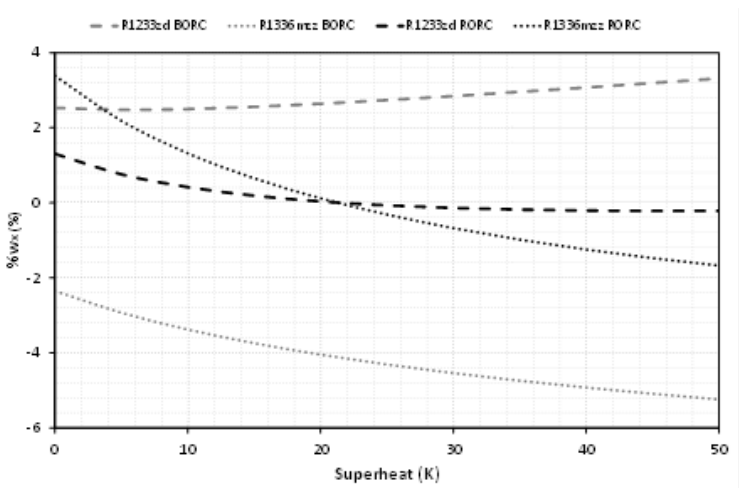

(c) increase font size

Fig. 4. Relative differences, taking HFC-245fa as reference, for expander power output varying the: (a) evaporating temperature, (b) condensing temperature, and (c) superheat. 


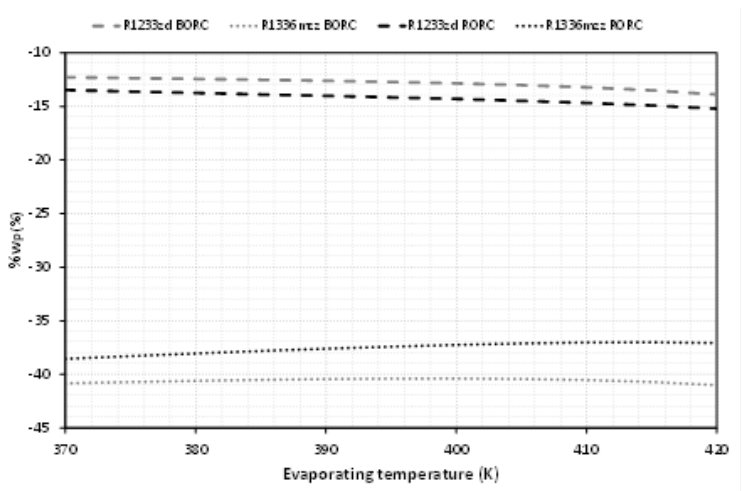

(a) increase font size

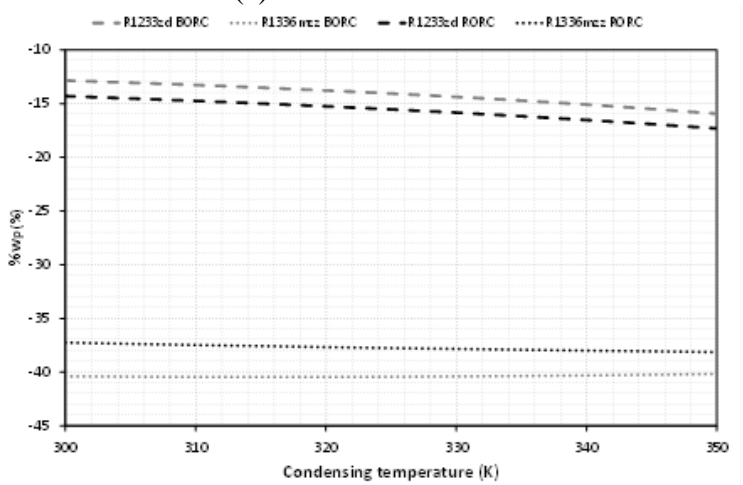

(b) increase font size

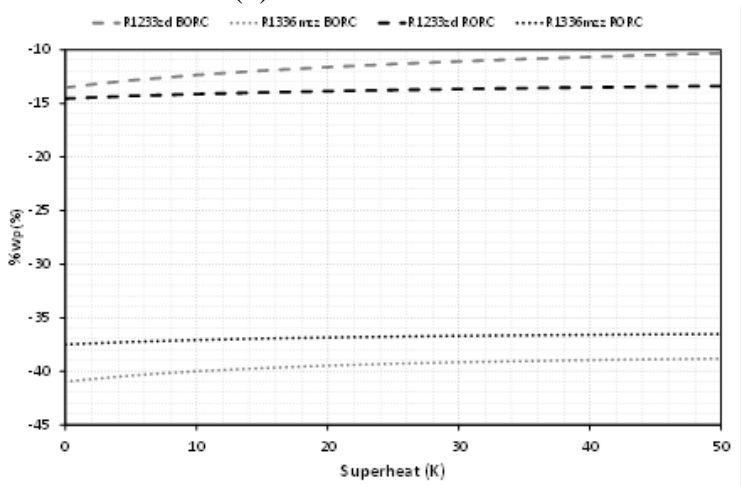

(c) increase font size

Fig. 5. Relative differences, taking HFC-245fa as reference, for pump power input varying the: (a) evaporating temperature, (b) condensing temperature, and (c) superheat. 


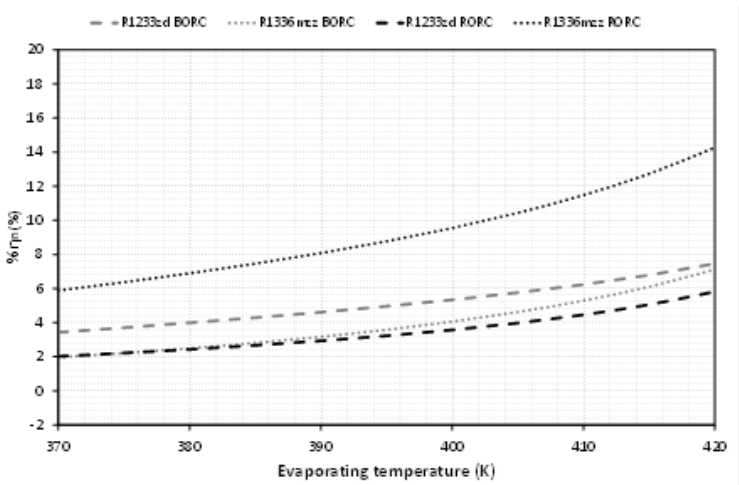

(a) increase font size

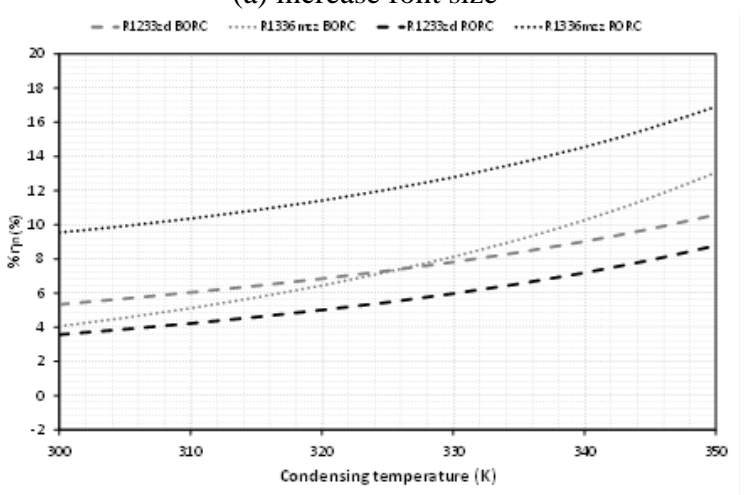

(b) increase font size

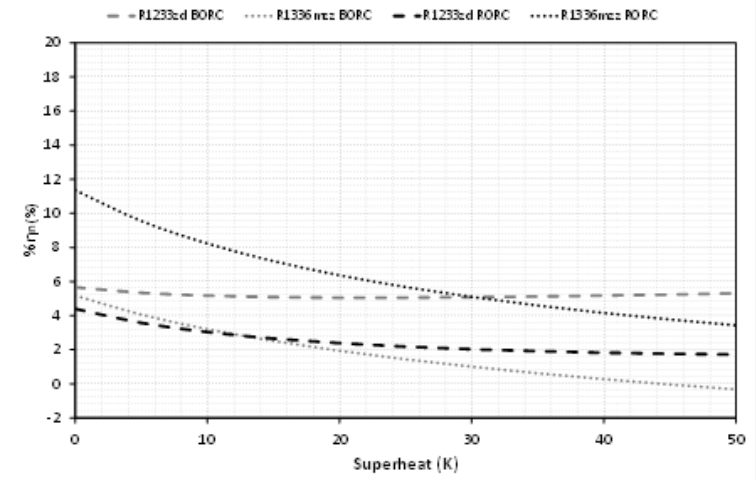

(c) increase font size

Fig. 6. Relative differences, taking HFC-245fa as reference, for net cycle efficiency varying the: (a) evaporating temperature, (b) condensing temperature, and (c) superheat. 


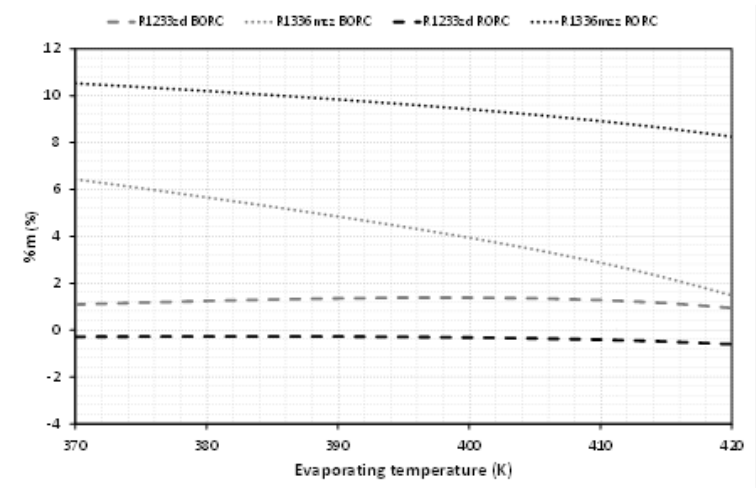

(a) increase font size

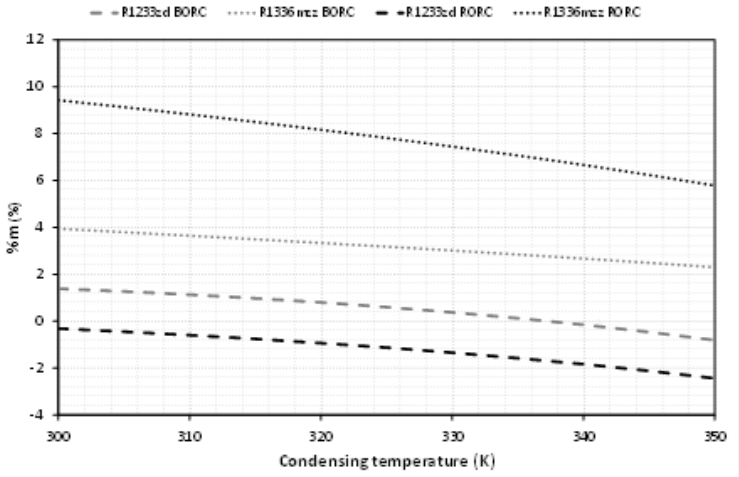

(b) increase font size

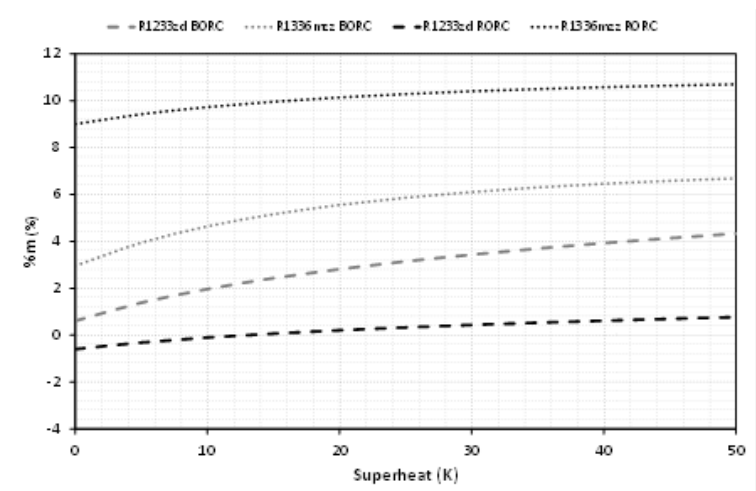

(c)

Fig. 7. Relative differences, taking HFC-245fa as reference, for mass flow rate varying the: (a) evaporating temperature, (b) condensing temperature, and (c) superheat. 


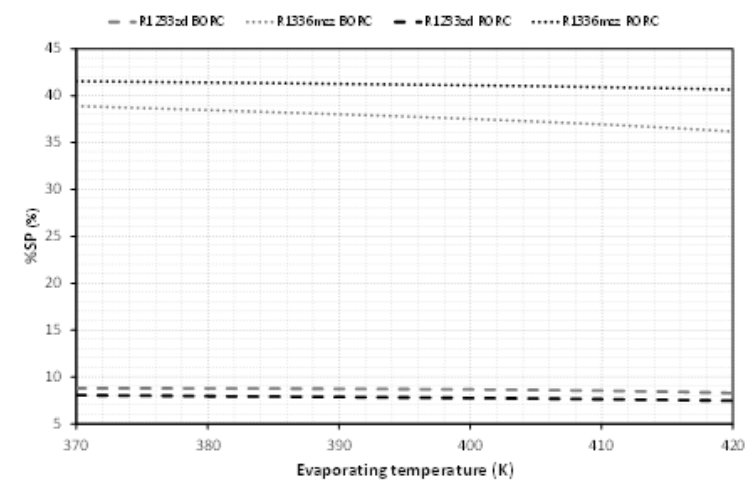

(a) increase font size

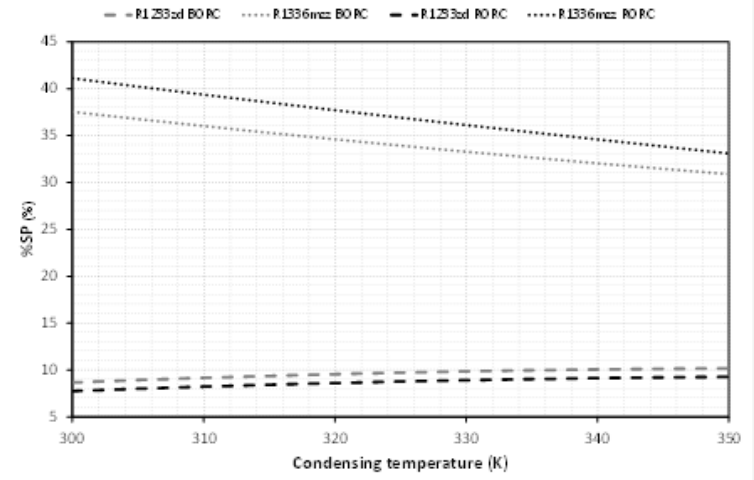

(b) increase font size

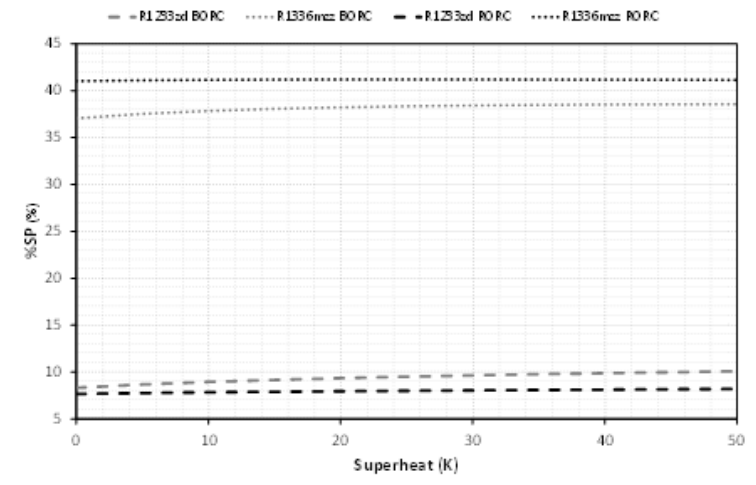

(c) increase font size

Fig. 8. Relative differences, taking HFC-245fa as reference, for turbine size parameter varying the: (a) evaporating temperature, (b) condensing temperature, and (c) superheat.

\section{FIGURE CAPTIONS}


Fig. 1. T-s diagram for HFC-245fa, HCFO-1233zd-E and HFO-1336mzz-Z.

Fig. 2. Basic Organic Rankine Cycle (BORC).

Fig. 3. Regenerative Organic Rankine Cycle (RORC).

Fig. 4. Relative differences, taking HFC-245fa as reference, for expander power output varying the: (a) evaporating temperature, (b) condensing temperature, and (c) superheat.

Fig. 5. Relative differences, taking HFC-245fa as reference, for pump power input varying the: (a) evaporating temperature, (b) condensing temperature, and (c) superheat.

Fig. 6. Relative differences, taking HFC-245fa as reference, for net cycle efficiency varying the: (a) evaporating temperature, (b) condensing temperature, and (c) superheat.

Fig. 7. Relative differences, taking HFC-245fa as reference, for mass flow rate varying the: (a) evaporating temperature, (b) condensing temperature, and (c) superheat.

Fig. 8. Relative differences, taking HFC-245fa as reference, for turbine size parameter varying the: (a) evaporating temperature, (b) condensing temperature, and (c) superheat. 
Table 1. Thermophysical properties of HFC-245fa, HCFO-1233zd-E and HFO1336mzz-Z.

\begin{tabular}{|c|c|c|c|}
\hline Parameters & HFC-245fa & $\begin{array}{l}\text { HCFO- } \\
\text { 1233zd-E }\end{array}$ & $\begin{array}{c}\text { HFO-1336mzz- } \\
\text { Z }\end{array}$ \\
\hline $\mathrm{T}_{\mathrm{c}}(\mathrm{K})$ & 427.16 & 438.75 & 444.45 \\
\hline $\mathrm{P}_{\mathrm{c}}(\mathrm{MPa})$ & 3.65 & 3.57 & 2.9 \\
\hline Mol. w. (kg/kmol) & 134 & 130.5 & 164 \\
\hline Slope & Dry & Dry & Dry \\
\hline OEL (ppm) & 300 & 300??source?? & $500(*)$ \\
\hline Flammability & Non flammable & Non flammable & Non flammable \\
\hline $\operatorname{ALT}(\mathrm{yr})$ & 7.6 & 0.07 & 0.0658 \\
\hline ODP & 0 & 0.00034 & 0 \\
\hline GWP & 1030 & 7 & 9 \\
\hline Boiling point $(\mathrm{K})$ & 287.96 & 291.12 & 306.55 \\
\hline Latent heat at boiling point $(\mathrm{kJ} / \mathrm{kg})$ & 196.23 & 195.52 & 165.67 \\
\hline Evaporating pressure at $400 \mathrm{~K}(\mathrm{MPa})$ & 2.21 & 1.80 & 1.28 \\
\hline Condensing pressure at $300 \mathrm{~K}(\mathrm{MPa})$ & 0.16 & 0.14 & 0.08 \\
\hline Vapour density at $300 \mathrm{~K}\left(\mathrm{~kg} / \mathrm{m}^{3}\right)$ & 9.13 & 7.65 & 5.38 \\
\hline Liquid density at $300 \mathrm{~K}\left(\mathrm{~kg} / \mathrm{m}^{3}\right)$ & 1333.5 & 1258.3 & 1359.5 \\
\hline $\begin{array}{l}\text { Vapour specific heat at } 300 \mathrm{~K} \\
(\mathrm{~kJ} / \mathrm{kg} \cdot \mathrm{K})\end{array}$ & 0.96 & 0.84 & 0.87 \\
\hline $\begin{array}{l}\text { Liquid specific heat at } 300 \text { K } \\
(\mathrm{kJ} / \mathrm{kg} \cdot \mathrm{K})\end{array}$ & 1.33 & 1.25 & 1.21 \\
\hline
\end{tabular}

(*) DuPont Allowable Exposure Limit (AEL) 
Table 2. Model equations for each configuration.

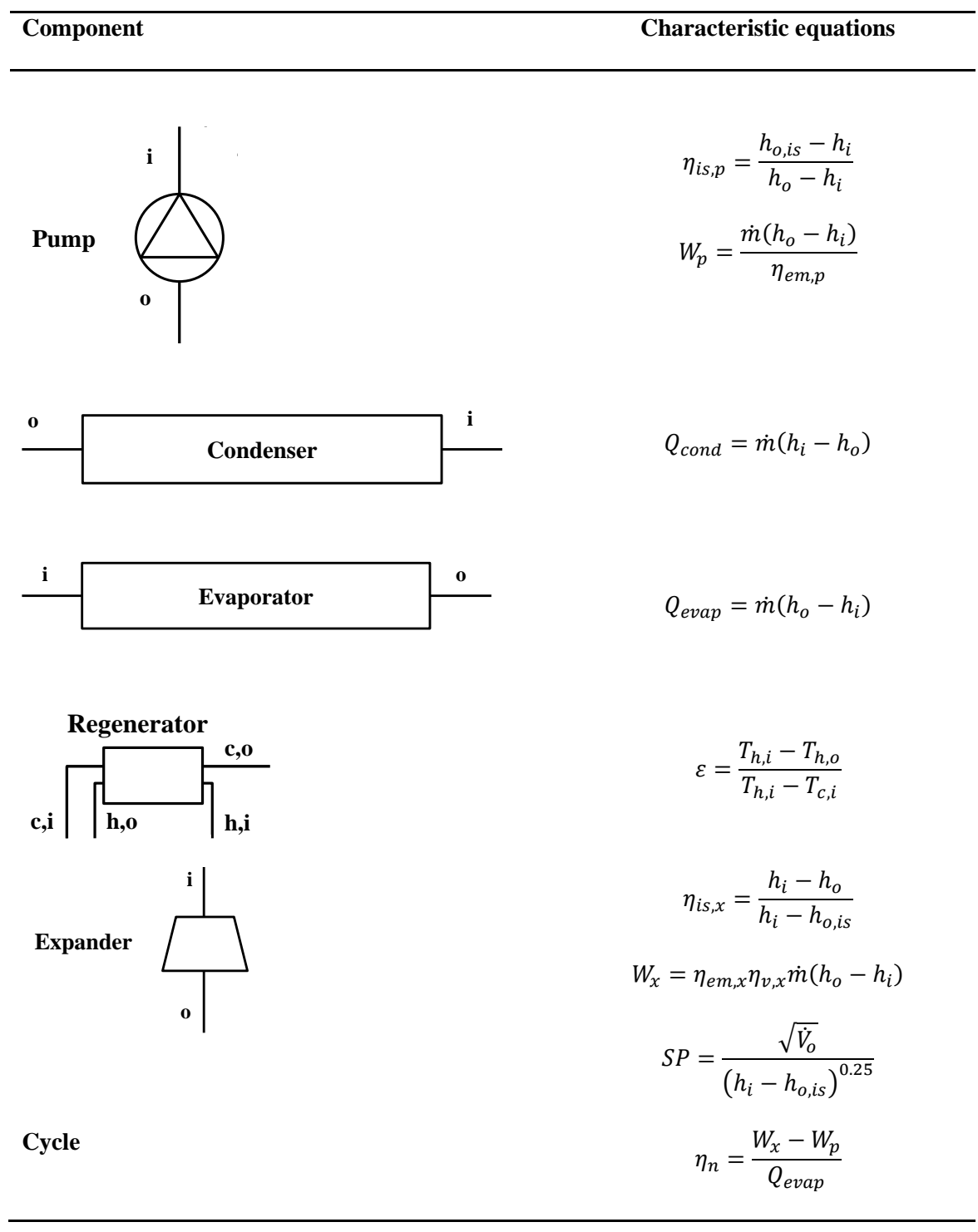


Table 3. Cycle operating parameters.

\begin{tabular}{lr}
\hline Parameters & Numeric values \\
\hline Condensing temperature $\left(T_{\text {cond }}\right)$ & $300 \mathrm{~K}-350 \mathrm{~K}(300 \mathrm{~K})$ \\
Evaporating temperature $\left(T_{\text {evap }}\right)$ & $370-420 \mathrm{~K}(400 \mathrm{~K})$ \\
Superheat & $0-50 \mathrm{~K}(5 \mathrm{~K})$ \\
Subcooling & $5 \mathrm{~K}$ \\
Regenerator effectiveness $(\varepsilon)$ & $80 \%$ \\
Efficiencies $\left(\eta_{i s, x}, \eta_{v, x}, \eta_{i s, p}\right)$ & $85 \%$ \\
Efficiencies $\left(\eta_{e m, x}\right)$ & $90 \%$ \\
Efficiencies $\left(\eta_{e m, p}\right)$ & $35 \%$ \\
\hline
\end{tabular}

